\title{
Electrocardiometry for Hemodynamic Categorization and Assessment of Fluid Responsiveness in Pediatric Septic Shock: A Pilot Observational Study
}

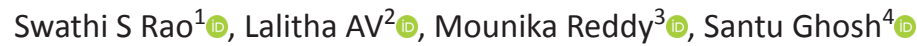

\begin{abstract}
Aim: To evaluate the utility of noninvasive electrocardiometry (ICON $\left.{ }^{\circledR}\right)$ for hemodynamic categorization and assessment of fluid responsiveness in pediatric septic shock.

Materials and methods: Pilot prospective observational study in a 12-bedded tertiary pediatric intensive care unit (PICU) in children aged between 2 months and 16 years with unresolved septic shock after a $20 \mathrm{~mL} / \mathrm{kg}$ fluid bolus. Those with cardiac index $(\mathrm{Cl})<3.3 \mathrm{~L} / \mathrm{min} / \mathrm{m}^{2}$ and systemic vascular resistance index (SVRI) $>1600 \mathrm{dyn} \mathrm{sec} / \mathrm{cm}^{5} / \mathrm{m}^{2}$ were classified as vasoconstrictive shock-electrocardiometry (VCEC) and those with $\mathrm{Cl}>5.5 \mathrm{~L} / \mathrm{min} / \mathrm{m}^{2}$ and SVRI $<1000 \mathrm{dyn} \mathrm{sec} / \mathrm{cm}^{5} / \mathrm{m}^{2}$ as vasodilated shock-electrocardiometry (VDEC). Fluid responsiveness was defined as a $10 \%$ increase in Cl with a $20 \mathrm{~mL} / \mathrm{kg}$ fluid bolus. Sepsis-induced myocardial dysfunction (SMD) was diagnosed on echocardiography. Outcomes studied included clinical shock resolution, length of PICU stay, and mortality.

Results: Thirty children were enrolled over 6 months with a median (interquartile range) age and pediatric risk of mortality (PRISM) III score of $87(21,108)$ months and $6.75(1.5,8.25)$, respectively; $14(46.6 \%)$ were boys and $4(13.3 \%)$ died. Clinically, $19(63.3 \%)$ children had cold shock and 11(36.7\%) had warm shock; however, 16(53.3\%) children had VDEC (including five with clinical cold shock) and 14(46.7\%) had VCEC using electrocardiometry. Fluid responsiveness was seen in 16(53.3\%) children, 10 in the VCEC group and 6 in the VDEC group. In the VCEC group, the responders had a significant rise in $\mathrm{Cl}$ and a fall in SVRI, while the responders in the VDEC group had a significant rise in Cl and SVRI. Fluid responders, compared to nonresponders, had a significantly higher stroke volume variation (SVV) before fluid bolus $(24.1 \pm 5.2 \%$ vs. $18.2 \pm 3.5 \%, p<0.001)$ and a higher reduction in SVV after fluid bolus ( $10.0 \pm 2.8 \%$ vs. $6.0 \pm 4.5 \%, p=0.006)$, higher lactate clearance $(p=0.03)$ and lower vasoactive-inotropic score $(p=0.04)$ at 6 hours, higher percentage of clinical shock resolution at $6(p=0.01)$ and 12 hours $(p=0.01)$, and lesser mortality $(p=0.002)$. Five (16.6\%) children with VCEC had SMD and were less fluid responsive $(p=0.04)$ with higher mortality $(p=0.01)$ compared to those without SMD. Conclusions and clinical significance: Continuous, noninvasive hemodynamic monitoring using electrocardiometry permits hemodynamic categorization and assessment of fluid responsiveness in pediatric septic shock. This may provide real-time guidance for optimal interventions, and thus, improve the outcomes.

Keywords: Cardiac output, Fluid bolus, Myocardial dysfunction, Noninvasive, Sepsis.

Indian Journal of Critical Care Medicine (2021): 10.5005/jp-journals-10071-23730
\end{abstract}

\section{INTRODUCTION}

Septic shock is a common cause of morbidity and mortality in children, especially in resource-limited settings. Sepsis in children causes hemodynamic instability through multiple mechanisms including heterogeneous vasodilatation, capillary leak, and myocardial dysfunction. Any of these may predominate at presentation and their relative contribution may be altered over time. ${ }^{1-6}$ Early and accurate identification of the underlying pathophysiology and hemodynamic assessment is critical for optimal management. Physical examination alone may not be sensitive enough to detect the subtle shifts in the hemodynamic status, which can have important implications for the treatment and outcomes. Also, the static hemodynamic measures do not reflect the dynamic process. Continuous cardiac output (CO) monitoring may allow better characterization of the hemodynamic status of children with septic shock. Though pulmonary artery catheter thermodilution technique is considered to be the gold standard for CO measurement, it is invasive and technically difficult with its inherent complications which preclude its routine use. ${ }^{7}$ Hence, there is a need for reliable noninvasive methods of continuous $\mathrm{CO}$ monitoring. Several noninvasive modalities like echocardiography, ultrasound cardiac output monitor (USCOM, Sydney, Australia),
${ }^{1}$ Department of Pediatrics, KS Hegde Medical College, Mangaluru, Karnataka, India

2,3 Department of Pediatric Intensive Care, St. John's Medical College and Hospital, Bangaluru, Karnataka, India

${ }^{4}$ Department of Biostatistics, St. John's Medical College and Hospital, Bangaluru, Karnataka, India

Corresponding Author: Mounika Reddy, Department of Pediatric Intensive Care, St. John's Medical College and Hospital, Bangaluru, Karnataka, India, Phone: +91 9855784739, e-mail:doc.mounikareddy@ gmail.com, mounika.reddy@stjohns.in

How to cite this article: Rao SS, Reddy M, Lalitha AV, Ghosh S. Electrocardiometry for Hemodynamic Categorization and Assessment of Fluid Responsiveness in Pediatric Septic Shock: A Pilot Observational Study. Indian J Crit Care Med 2021;25(2):185-192.

Source of support: Nil

Conflict of interest: None

bioimpedance, etc., have been developed and investigated, but their use is limited by the lack of availability and expertise. ${ }^{7-9}$ Bedside echocardiography with direct visualization of the heart 
and great vessels, though widely being employed, is noncontinuous and subjective. ${ }^{9,10}$

Early recognition and appropriate interventions result in favorable outcomes in pediatric septic shock. Current septic shock resuscitation guidelines focus on early, rapid administration of large volume intravenous fluids followed by optimal vasoactive medication infusions for fluid-refractory shock. 3,11 These guidelines are widely used, though based on scant evidence. Aggressive fluid resuscitation and subsequent fluid overload have been shown to result in worse patient outcomes. ${ }^{12}$ As both under- and over-resuscitation are detrimental, accurate estimation of fluid responsiveness becomes important. Fluid responsiveness is defined as an increase in stroke volume or $\mathrm{CO}$ in response to volume loading. There is no ideal diagnostic test for assessing fluid responsiveness in children. Static variables like central venous pressure and cardiac chamber volumes and pressures poorly predict fluid responsiveness. ${ }^{12}$ Dynamic measures based on the heart-lung interactions and changes in stroke volume have a better diagnostic accuracy; an increase in the stroke volume or CO by 10 to $15 \%$ is believed to predict the fluid responsiveness. ${ }^{13,14}$ Among various CO-measuring techniques, variation in the aortic blood flow peak velocity measured by a transthoracic or transesophageal Doppler echocardiography consistently predicted the fluid responsiveness in children. ${ }^{15}$

ICON $^{\circledR}$ based on Electrical Cardiometry ${ }^{\mathrm{TM}}(\mathrm{EC})$ technology (Osypka Medical $\mathrm{GmbH}$, Berlin, Germany) is a noninvasive, continuous hemodynamic monitoring device. It determines the $\mathrm{CO}$ by measuring variations in the thoracic electrical bioimpedance with phases of a cardiac cycle. During diastole, the erythrocytes in the aorta assume a random orientation (more impedance), while during systole the pulsatile blood flow causes them to align parallel to both the blood flow and the electrical current (less impedance). The magnitude of the maximum rate of change of impedance with a change in the orientation of erythrocytes gives a peak aortic blood flow acceleration and stroke volume. ${ }^{16}$ Cardiac index $(\mathrm{Cl})$, systemic vascular resistance index (SVRI), cardiac contractility, stroke volume variation (SVV) and thoracic fluid content (TFC) are derived using complex mathematical formulae and patented algorithms. The accuracy and the clinical utility of electrocardiometry have been validated against other measures of CO like direct Fick's method, thermodilution, and transthoracic and transesophageal echocardiography in a wide spectrum of patient conditions and populations across all ages, including critically ill patients, intraoperative settings, cardiac catheterization, and congenital heart diseases. ${ }^{17-24}$ However, it has not been studied in pediatric septic shock.

The primary objective of our study was to evaluate the utility of electrocardiometry for hemodynamic categorization of pediatric septic shock and assessment of fluid responsiveness.

\section{Materials and Methods}

This was a pilot prospective observational study done over a period of six months from June 2018 to November 2018 in the pediatric intensive care unit (PICU) of a tertiary referral hospital in South India. The study was approved by the institute ethics committee, and informed consent was obtained from the parents of all the subjects.

Children aged between 2 months and 16 years admitted to PICU with septic shock which remained unresolved after a $20 \mathrm{~mL} /$ $\mathrm{kg}$ isotonic fluid bolus were included in the study. Those with unrepaired congenital heart disease, cardiomyopathy, chronic hepatic or renal disease, and evidence of pulmonary embolism or dysrhythmia, and those in a moribund state and expected to die within 24 hours were excluded. At enrollment, the ICON ${ }^{\circledR}$ surface electrodes were applied for continuous hemodynamic monitoring. All the patients then received another $20 \mathrm{~mL} / \mathrm{kg}$ isotonic saline bolus over 15 to 20 minutes followed by further management as per standard pediatric septic shock management guidelines. ${ }^{3,11}$

The demographic details, clinical features, diagnoses, and severity of illness scores [pediatric risk of mortality (PRISM) III] were recorded at enrollment on a prestructured proforma. The hemodynamic variables including $\mathrm{Cl}$, SVRI, SVV, and TFC were captured from ICON ${ }^{\circledR}$ at baseline (before bolus) and then at 1 (after bolus), 6, 12, and 24 hours along with the relevant clinical and laboratory parameters. All the patients underwent a bedsidefocused transthoracic 2D echocardiography by the primary investigator (trained in pediatric functional echocardiography) within the 6 hours of shock recognition using a portable device (Sonosite, Washington, USA) to assess the adequacy of the intravascular volume and myocardial function. Outcome measures including inotrope requirement, time for clinical shock resolution, length of PICU stay, and mortality were collected. The patients were followed up until discharge from the PICU or death, whichever occurred earlier.

\section{Definitions}

Pediatric septic shock was defined as per the American College of Critical Care Medicine (ACCM) guidelines. ${ }^{3}$ Clinical cold shock was defined by cold extremities, feeble or absent peripheral pulses, and capillary refill time (CRT) >3 seconds; while warm shock was defined by warm extremities, bounding peripheral pulses, and brisk CRT ( $<1$ second). $\mathrm{Cl}$ of 3.3 to $5.5 \mathrm{~L} / \mathrm{min} / \mathrm{m}^{2}$ and SVRI of 1000 to 1600 dyn second $/ \mathrm{cm}^{5} / \mathrm{m}^{2}$ on electrocardiometry were considered to be normal. $\mathrm{Cl}<3.3 \mathrm{~L} / \mathrm{min} / \mathrm{m}^{2}$ with SVRI $>1600$ dyn second $/ \mathrm{cm}^{5} / \mathrm{m}^{2}$ was classified as vasoconstricted shock-electrocardiometry (VCEC), while $\mathrm{Cl}>5.5 \mathrm{~L} / \mathrm{min} / \mathrm{m}^{2}$ with SVRI $<1000$ dyn second $/ \mathrm{cm}^{5} / \mathrm{m}^{2}$ was classified as vasodilated shock-electrocardiometry (VDEC). ${ }^{25}$ Fluid responsiveness was defined as a $10 \%$ increase in $\mathrm{Cl}$ in response to volume loading (20 mL/kg normal saline). ${ }^{13}$ Shock resolution was defined clinically as achievement of all of the following: heart rate and blood pressure normal for age and gender, normal CRT, good peripheral and central pulses, urine output $>1 \mathrm{~mL} / \mathrm{kg} /$ hour, and normal mental status. $^{3}$ Six-hour lactate clearance was calculated as: (baseline lactate -6 -hour lactate)/baseline lactate $\times 100 \% .{ }^{26}$ Vasoactive inotropic score(VIS) was calculated as: dopamine dose (mcg/ $\mathrm{kg} / \mathrm{min})+$ dobutamine dose $(\mathrm{mcg} / \mathrm{kg} / \mathrm{min})+100 \times$ epinephrine dose $(\mathrm{mcg} / \mathrm{kg} / \mathrm{min})+100 \times$ norepinephrine dose $(\mathrm{mcg} / \mathrm{kg} /$ $\mathrm{min})+10 \times$ milrinone dose $(\mathrm{mcg} / \mathrm{kg} / \mathrm{min})+10,000 \times$ vasopressin dose $(\mathrm{U} / \mathrm{kg} / \mathrm{min})^{27}$

Sepsis-induced myocardial dysfunction (SMD) was defined as systolic and/or diastolic dysfunction of the left ventricle (LV) and/or right ventricle (RV). ${ }^{28}$ Systolic dysfunction of the LV was defined as LV ejection fraction (EF) $<50 \%$ as determined by a combination of visual assessment and measured LVEF. The LVEF was calculated using the formula: [LV end-diastolic dimension squared $\left(\right.$ LVEDD $^{2}$ ) - LV end-systolic dimension squared $\left(\right.$ LVESD $\left.\left.^{2}\right)\right] /$ LVEDD $^{2}$ expressed as a percentage (calculated by the machine software).The normal LVEF in children is 56 to $78 \%$. LV diastolic dysfunction was detected by a pulse wave Doppler assessment of transmitral valve inflow velocity patterns focusing on the early $(E)$ and late (A) diastolic filling velocities, the E/A ratio. ${ }^{6}$ RV function was categorized as abnormal in the presence of RV dilatation ( $\geq \mathrm{LV}$ size) and paradoxical septal motion. ${ }^{29}$ 


\section{Statistical Analysis}

This being a pilot study, a sample size of 30 was considered. The data were analyzed using the statistical software-statistical package for social sciences, version 20 (SPSS, IBM, Chicago, IL, USA). Summary statistics are presented as frequencies and proportions for categorical variables, as mean and standard deviation for parametric continuous variables, and as median and interquartile range (IQR) for nonparametric continuous variables. Intergroup comparisons were performed using chi-square test or Fisher exact test for categorical data, Student $T$-test or Mann-Whitney $U$-test for continuous data, and paired $T$-test for before-after comparisons. Repeated measures analysis of variance was used to compare the differences in the trends of $\mathrm{Cl}$, SVRI, heart rate, and pulse pressure among the fluid responders and nonresponders. All tests of significance were two tailed, and a $p$ value of $<0.05$ was considered to be statistically significant.

\section{Results}

A total of 30 children with unresolved septic shock after a $20 \mathrm{~mL} /$ $\mathrm{kg}$ isotonic fluid bolus were included in the study (Flowchart 1). The median (IQR) age of the study population was $87(21,108)$ months and 14 (46.6\%) were boys. The most common focus of the infection was the lower respiratory tract (46\%) followed by a bloodstream infection (26.6\%). The infection-causing pathogen could be identified by a microbiological culture in 21 (70\%) patients. The median (IQR) PRISM III score of the cohort was $6.75(1.5,8.25)$. Figure 1 represents the flow of study patients.

Among the 30 children, on clinical examination, 19 (63.3\%) had a cold shock and the remaining 11 (36.7\%) had a warm shock. However, on electrocardiometry assessment, only 11 of the 19 patients with a clinical cold shock were determined to have VCEC shock. Among the other 8 patients, 5 had VDEC shock, while the other 3 had normal Cl with high SVRI ( $>1600$ dyn second $/ \mathrm{cm}^{5} / \mathrm{m}^{2}$ ) and were included in the VCEC group for analysis. All the 11 children with clinical warm shock had VDEC shock. Thus, a total of 16 (53.3\%) children had VDEC shock and 14 (46.7\%) had VCEC shock (Fig. 1). On invasive arterial blood pressure monitoring, the mean pulse pressure in cold VCEC $(n=14)$, cold VDEC $(n=5)$, and warm VDEC $(n=11)$ shock was $32.8 \pm 12.7,38.4 \pm 7.6$, and $44.2 \pm 8.8 \mathrm{~mm} \mathrm{Hg}$, respectively $(p=0.04)$.

The electrocardiometry measurements were obtained from the 30 patients over the first 24 hours of shock management. The baseline $\mathrm{Cl}$ and SVRI at enrollment and the changes noted with the second fluid bolus ( $20 \mathrm{~mL} / \mathrm{kg}$ isotonic saline) are presented in Table 1. Among the patients with VDEC shock, there was no significant difference between those presenting as cold shock $(n=5)$ or warm

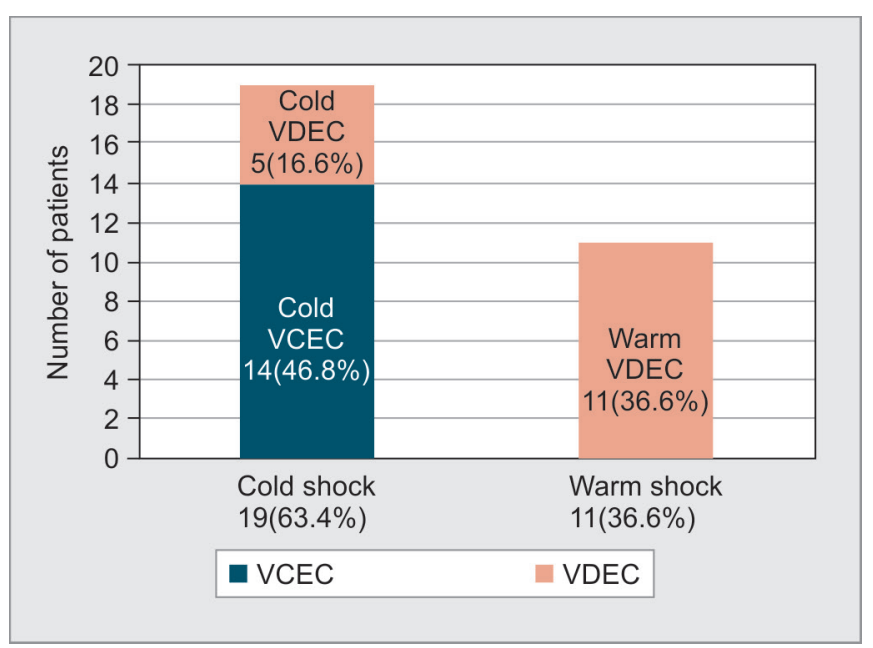

Fig. 1: Hemodynamic categorization of children with septic shock unresolved after $20 \mathrm{~mL} / \mathrm{kg}$ isotonic fluid bolus $(n=30)$ based on clinical examination and electrocardiometry (VCEC, vasoconstricted shockelectrocardiometry; VDEC, vasodilated shock-electrocardiometry)

Flowchart 1: Study flowchart (Cl, cardiac index; SVRI, systemic vascular resistance index; VDEC, vasodilated shock-electrocardiometry; VCEC, vasoconstricted shock-electrocardiometry)

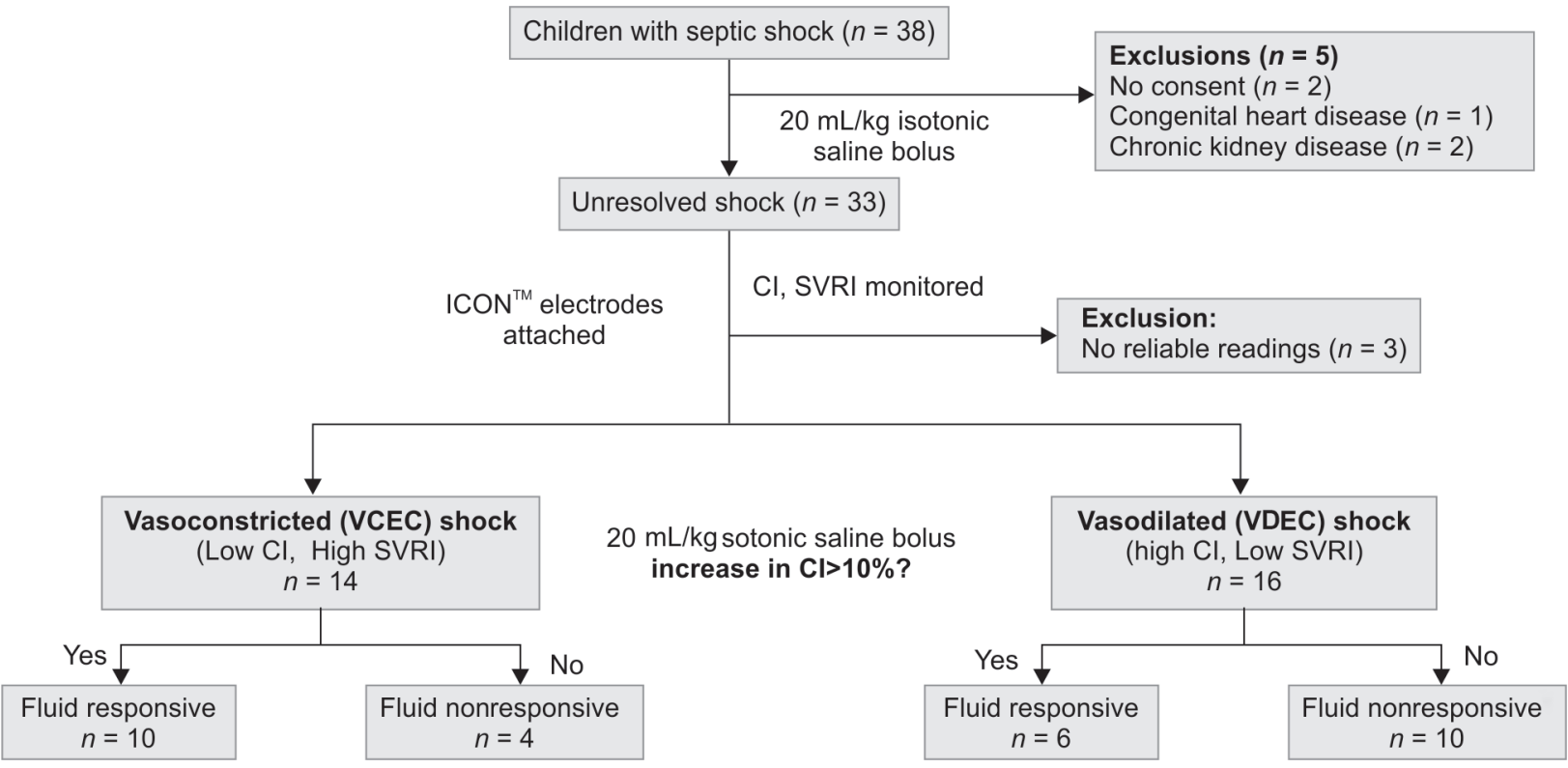


Table 1: Baseline hemodynamic parameters of the study population (using electrocardiometry) and changes with fluid bolus $(20 \mathrm{~mL} / \mathrm{kg}$ normal saline)

\begin{tabular}{|c|c|c|c|c|c|}
\hline \multicolumn{6}{|c|}{ Baseline hemodynamic parameters on electrocardiometry } \\
\hline \multicolumn{2}{|l|}{ Type of shock } & $\begin{array}{l}\text { Cold VCEC } \\
(n=14)\end{array}$ & $\begin{array}{l}\text { Cold VDEC } \\
(n=5)\end{array}$ & \multicolumn{2}{|c|}{$\begin{array}{l}\text { Warm VDEC } \\
(n=11)\end{array}$} \\
\hline \multicolumn{2}{|l|}{$\mathrm{Cl}\left(\mathrm{L} / \mathrm{min} / \mathrm{m}^{2}\right)^{*}$} & $3.2 \pm 0.7$ & $6.1 \pm 0.6$ & \multicolumn{2}{|c|}{$6.5 \pm 0.8$} \\
\hline \multicolumn{2}{|c|}{ SVRI (dyn-sec $\left./ \mathrm{cm}^{5} / \mathrm{m}^{2}\right)^{*}$} & $2295 \pm 81097$ & $974 \pm 89$ & \multicolumn{2}{|c|}{$913 \pm 102$} \\
\hline \multicolumn{6}{|c|}{ Changes in the hemodynamic parameters with fluid bolus } \\
\hline Parameter & Group & Before bolus & \multicolumn{2}{|c|}{ After bolus } & pvalue \\
\hline \multirow[t]{4}{*}{$\mathrm{Cl}\left(\mathrm{L} / \mathrm{min} / \mathrm{m}^{2}\right)$} & $\begin{array}{l}\text { VCEC fluid } \\
\text { responders } \\
(n=10)\end{array}$ & $3.2 \pm 0.6$ & \multicolumn{2}{|c|}{$3.9 \pm 0.2$} & 0.001 \\
\hline & $\begin{array}{l}\text { VCEC fluid } \\
\text { nonresponders } \\
(n=4)\end{array}$ & $3.2 \pm 0.9$ & \multicolumn{2}{|c|}{$3.2 \pm 0.5$} & 0.64 \\
\hline & $\begin{array}{l}\text { VDEC fluid } \\
\text { responders } \\
(n=6)\end{array}$ & $5.7 \pm 1.1$ & \multicolumn{2}{|c|}{$6.2 \pm 1.1$} & $<0.001$ \\
\hline & $\begin{array}{l}\text { VDEC fluid } \\
\text { nonresponders } \\
(n=10)\end{array}$ & $6.5 \pm 1.5$ & \multicolumn{2}{|c|}{$5.6 \pm 1.1$} & $<0.001$ \\
\hline \multirow[t]{4}{*}{$\begin{array}{l}\text { SVRI (dyn-sec/ } \\
\left.\mathrm{cm}^{5} / \mathrm{m}^{2}\right)\end{array}$} & $\begin{array}{l}\text { VCEC fluid } \\
\text { responders } \\
(n=10)\end{array}$ & $2111 \pm 104$ & \multicolumn{2}{|c|}{$4 \quad 1742 \pm 579$} & 0.003 \\
\hline & $\begin{array}{l}\text { VCEC fluid } \\
\text { nonresponders } \\
(n=4)\end{array}$ & rs $2961 \pm 107$ & \multicolumn{2}{|c|}{$2860 \pm 560$} & 0.51 \\
\hline & $\begin{array}{l}\text { VDEC fluid } \\
\text { responders } \\
(n=6)\end{array}$ & $930 \pm 68$ & \multicolumn{2}{|c|}{$1239 \pm 132$} & $<0.001$ \\
\hline & $\begin{array}{l}\text { VDEC fluid } \\
\text { nonresponders } \\
(n=10)\end{array}$ & $968 \pm 34$ & \multicolumn{2}{|c|}{$1039 \pm 114$} & 0.71 \\
\hline
\end{tabular}

*Mean \pm Standard deviation; $\mathrm{Cl}$, cardiac index; SVRI, systemic vascular resistance index; VCEC, vasoconstrictive shock-electrocardiometry; VDEC, vasodilated shock-electrocardiometry

shock $(n=11)$ in terms of $\mathrm{Cl}\left(6.1 \pm 0.6 \mathrm{vs.} 6.5 \pm 0.8 \mathrm{~L} / \mathrm{min} / \mathrm{m}^{2}, p=0.92\right)$ and SVRI ( $974 \pm 89$ vs. $913 \pm 102$ dyn second $\left./ \mathrm{cm}^{5} / \mathrm{m}^{2}, p=0.44\right)$.

Fluid responsiveness (as defined by an increase in $\mathrm{Cl}$ by $10 \%$ on electrocardiometry) was seen in 16 (53.3\%) patients, 10 of 14 in the VCEC group and 6 of 16 in the VDEC group. In the VCEC group, 1 hour after fluid bolus, the responders had a significant rise in $\mathrm{Cl}$ and a fall in SVRI, while there was a significant rise in $\mathrm{Cl}$ and SVRI among the responders in the VDEC group. The trends of the $\mathrm{Cl}$, SVRI, heart rate, and pulse pressure in fluid responders and nonresponders over the first 24 hours of shock management are presented in Figures 2 and 3. On repeated measures ANOVA, in the VCEC group, a significant difference was noted between the responders and the nonresponders in the $\mathrm{Cl}$ trend $(p=0.002)$ with a gradual improvement in $\mathrm{Cl}$ in the responders, while the difference in the trends of SVRI $(p=0.132)$ was not significant, though the nonresponders had a persistently high SVRI. In the VDEC group, the difference between the responders and the nonresponders was significant in the $\mathrm{Cl}(p=0.034)$ and SVRI $(p=0.047)$ trends, whereas the VDEC nonresponders had a gradual fall in $\mathrm{Cl}$. The trends of heart rate and pulse pressure did not show any significant difference between fluid responders and nonresponders in either VCEC or VDEC groups.
The comparison of various hemodynamic and outcome parameters between fluid responders and nonresponders (as defined by electrocardiometry) is depicted in Table 2. The fluid responders, as compared to the nonresponders, had a significantly higher SVV before the fluid bolus and a higher reduction in SVV after the fluid bolus. Though the TFC was similar in both groups before the fluid bolus, the fluid nonresponders had a higher increase in TFC after the fluid bolus than the responders. There was no difference between the two groups in the fall in heart rate or improvement in mean arterial pressure postbolus.

The fluid responders had better outcomes as compared to the nonresponders with higher lactate clearance and lower VIS at 6 hours, higher percentage of clinical resolution of shock at 6 and 12 hours, and lesser mortality. Among the 30 children, 4 (13.3\%) died, all belonged to the VCEC group and were fluid nonresponders. There was no mortality in the VDEC group. The overall median (IQR) length of PICU stay among the survivors was $5(3,8)$ days.

All the patients underwent screening 2D echocardiography within the first 6 hours of shock management. The echocardiography $\mathrm{EF}$ and corresponding electrocardiometry $\mathrm{Cl}$ showed a strong positive correlation (Pearson correlation coefficient $0.72, p=0.001$ ). SMD was detected on 2D echocardiography in five (16.6\%) children, all of them belonging to the VCEC group. Within the VCEC group, those with SMD had a significantly low mean baseline $\mathrm{Cl}$ as compared to those without SMD $(2.75 \pm 0.33$ vs. $3.53 \pm 0.47 \mathrm{~L} /$ $\left.\mathrm{min} / \mathrm{m}^{2}, p<0.001\right)$. Also, those with SMD, when compared to those without SMD, were less fluid responsive (20 vs. $89 \%, p=0.04)$ and had a higher mortality (60 vs. $11 \%, p=0.01$ ).

\section{Discussion}

Pediatric septic shock has traditionally been categorized as cold and warm shock based on the clinical examination inferring the peripheral vasoconstriction and vasodilation, respectively. Cold shock is considered to be a hypodynamic, high vascular tone state, with inodilators being the preferred drugs, while warm shock is a hyperdynamic low vascular tone state, warranting the early use of vasopressors. ${ }^{3}$ Children are believed to differ from adults in shock pathophysiology with reduced $\mathrm{CO}$ and increased systemic vascular resistance being commoner in children in contrast to the predominant manifestation of systemic vasodilation in adults, resulting in the usual presentation of a septic shock as cold shock in children. ${ }^{1,4}$ Ceneviva et al. ${ }^{5}$ studied the hemodynamic patterns in fluid-refractory ( $\geq 60 \mathrm{~mL} / \mathrm{kg}$ in the first hour), dopamineresistant pediatric septic shock $(n=50)$ based on pulmonary artery catheterization, and reported that a greater proportion of children (58\%) had vasoconstrictive shock (low Cl, high SVRI), 20\% had vasodilated shock (low SVRI, high $\mathrm{CI}$ ), and $22 \%$ had both low $\mathrm{Cl}$ and low SVRI. Lately, the clinical classification of pediatric septic shock into cold and warm shock has been proven to be unreliable since many children presenting with clinical cold shock may have an underlying vasodilated state. ${ }^{4,6}$ In a study of 48 children with septic shock by Ranjit et al., ${ }^{6}$ most (85.5\%) had wide pulse pressure (>40 $\mathrm{mm} \mathrm{Hg}$ ) on invasive blood pressure monitoring suggesting a vasodilated state including 14 of the 21 children with clinical cold shock. It has been proposed that a low $\mathrm{CO}$ due to either uncorrected hypovolemia or an underlying SMD can lead to a clinical picture of cold shock despite the vasodilated state.

Accurate hemodynamic assessments are critical to guide therapy (including fluids, vasoactives, and inotropes) in pediatric septic shock. We used electrocardiometry $\left(\right.$ ICON $\left.^{\mathrm{Tm}}\right)$ to evaluate the hemodynamic 

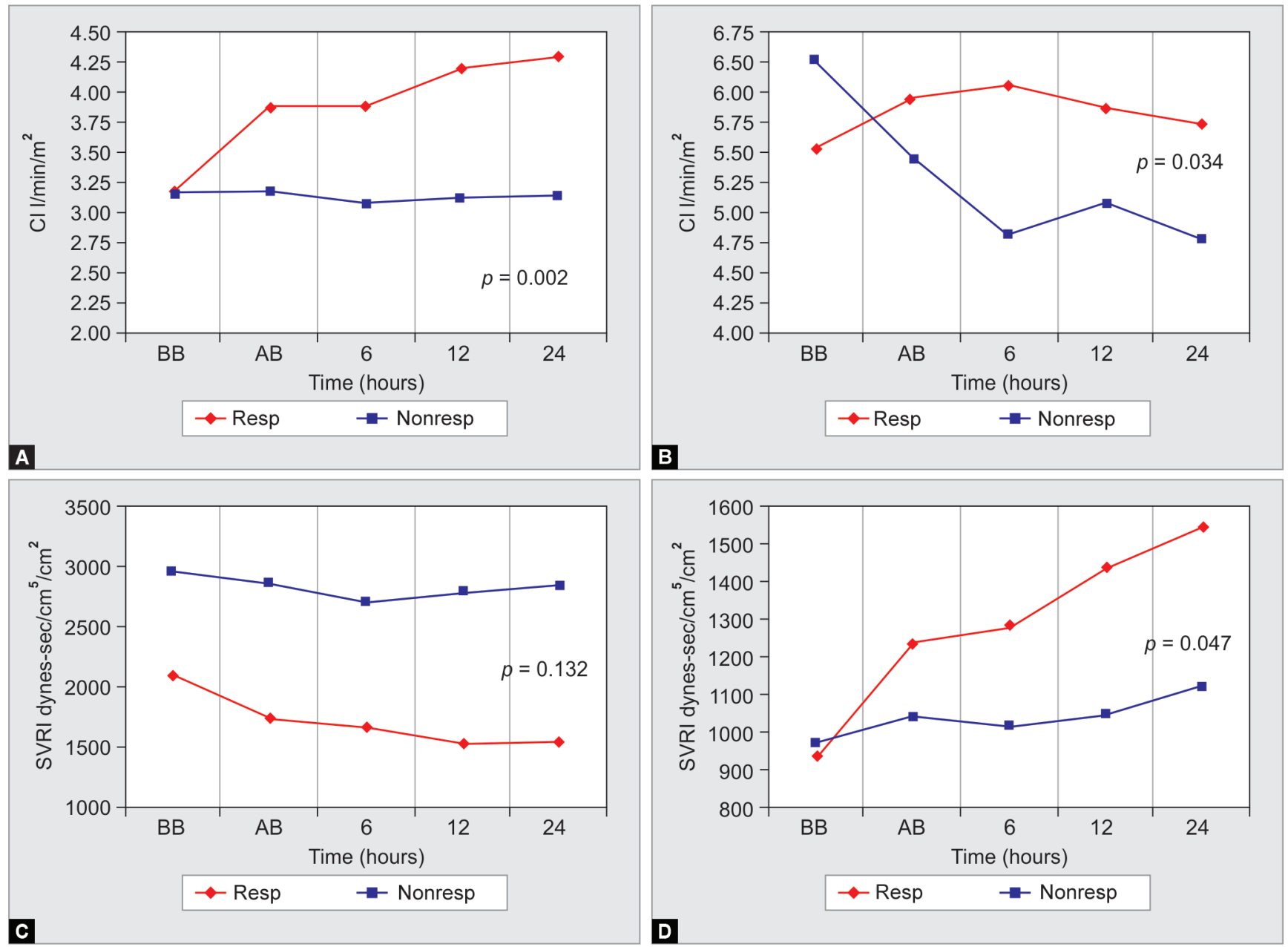

Fig. 2: Comparison of the trends of cardiac index and systemic vascular resistance index between fluid responders and nonresponders: (A) $\mathrm{Cl}$ trends in VCEC; (B) CI trends in VDEC; (C) SVRI trends in VCEC; (D) SVRI trends in VDEC (Cl, cardiac index; SVRI, systemic vascular resistance index; VCEC, vasoconstricted shock-electrocardiometry; VDEC, vasodilated shock-electrocardiometry; Resp, fluid responders; Nonresp, fluid nonresponders; $B B$, before bolus; $A B$, after bolus)

state of 30 children with septic shock refractory to initial fluid resuscitation with a $20 \mathrm{~mL} / \mathrm{kg}$ isotonic fluid bolus and compared it with clinical categorization into cold and warm shock. We found that $53.3 \%$ of children had an underlying hyperdynamic vasodilated state (VDEC shock) as the cause for persisting circulatory instability with high $\mathrm{Cl}$ and low SVRI. Though all the children with clinical warm shock had vasodilated state as per electrocardiometry, $26.3 \%$ of those with clinical cold shock were also found to have vasodilated state. In a study by Ranjit et al., ${ }^{30}$ of a total of 27 patients with vasodilated shock as determined by wide pulse pressure (>40 mm Hg), 17 (63\%) had clinical cold shock and 10 had warm shock. However, in our study, with invasive arterial blood pressure monitoring, the mean pulse pressure in cold shock (both VCEC and VDEC shock) was $<40 \mathrm{~mm} \mathrm{Hg}$, while in warm shock it was $>40 \mathrm{~mm} \mathrm{Hg}$. Hence, even a pulse pressure cutoff of $40 \mathrm{~mm} \mathrm{Hg}$ may not appropriately differentiate between vasoconstrictive and vasodilated shock as defined by $\mathrm{Cl}$ and SVRI. Among the patients with VDEC shock, there was no significant difference between those presenting with cold shock or warm shock in terms of $\mathrm{Cl}(p=0.92)$ and SVRI $(p=0.44)$, again reiterating that clinical examination alone may not help with appropriate pathophysiological categorization of pediatric septic shock.
When we used electrocardiometry to define the fluid responsiveness as a $10 \%$ increase in Cl with a $20 \mathrm{~mL} / \mathrm{kg}$ isotonic fluid bolus, we found that it well differentiated the fluid responders from the nonresponders with the fluid responders having significantly better outcomes including higher lactate clearance and lower VIS at 6 hours, higher percentage of clinical resolution of shock at 6 and 12 hours, and lesser mortality, as compared to nonresponders. As anticipated, the fluid responders had a significantly higher baseline SVV and greater fall in SVV with the fluid bolus as compared to nonresponders; what was notable was that the TFC, though similar in both groups before the fluid bolus, increased significantly after the bolus in the fluid nonresponders, possibly reflecting the fluid leaking out of the intravascular space and accumulating in the lungs and the interstitial spaces. The heart rate and pulse pressure trends were not different in fluid responders and nonresponders exposing their limitation in shock monitoring. We also noted that 10 of 16 children with VDEC had a reduction in $\mathrm{Cl}$ following fluid bolus. This may be observed in early sepsis when the CO initially increases to maintain the mean arterial pressure in cases with profound vasoplegia and then falls with fluid loading as the SVRI goes up. ${ }^{30}$ 

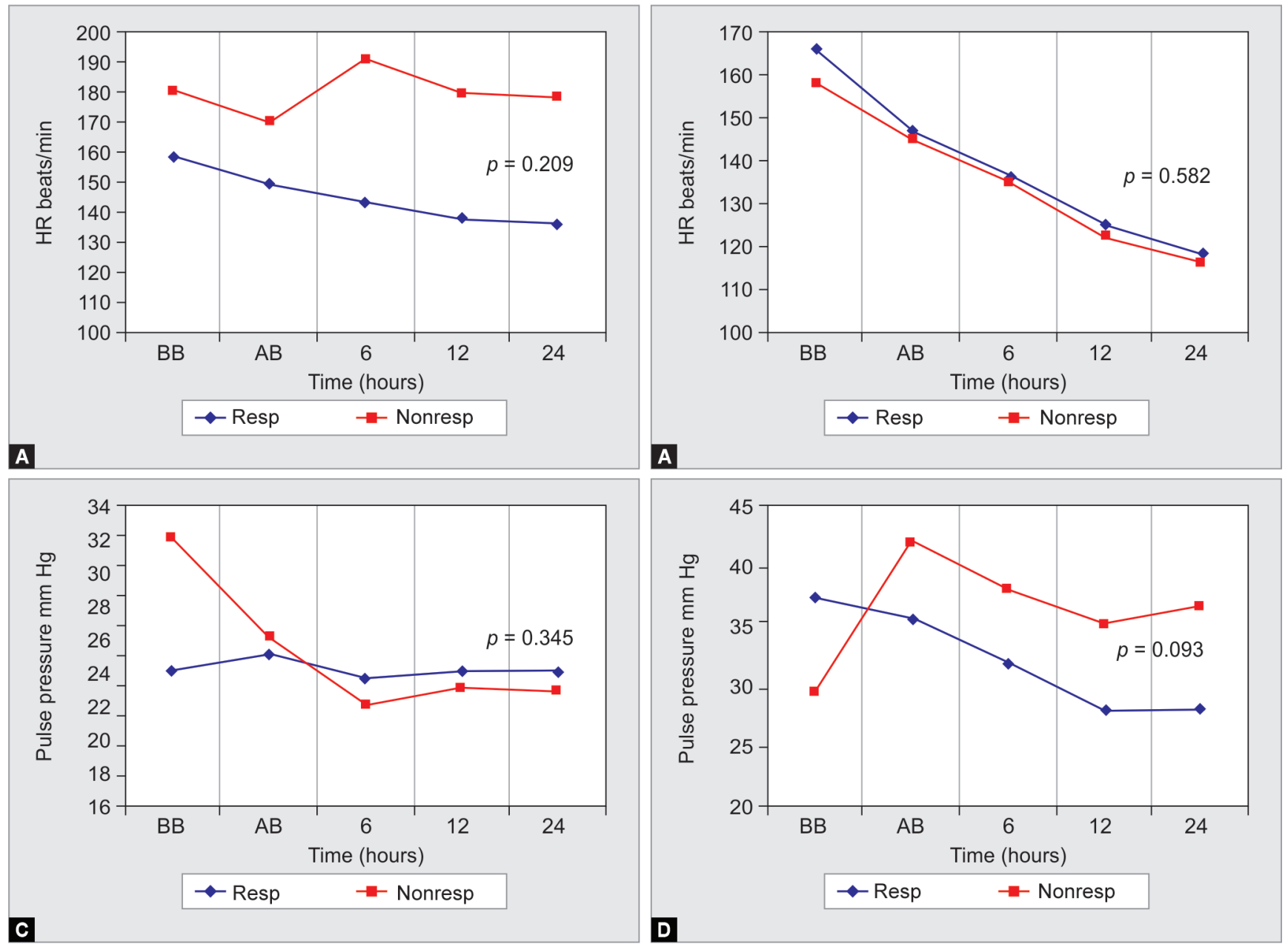

Fig. 3: Comparison of the trends of heart rate and pulse pressure between fluid responders and nonresponders: (A) HR trends in VCEC; (B) HR trends in VDEC; (C) PP trends in VCEC; (D) PP trends in VDEC (HR, heart rate; PP, pulse pressure; VCEC, vasoconstricted shock-electrocardiometry; VDEC, vasodilated shock-electrocardiometry; Resp, fluid responders; Nonresp, fluid nonresponders; BB, before bolus; AB, after bolus)

Two-dimensional echocardiography within 6 hours of enrolment detected SMD in five (16.6\%) children, all of them belonging to the VCEC group. These children had lower baseline $\mathrm{Cl}$, were less fluid responsive, and had higher mortality. Though in a study by Ranjit et al. ${ }^{6}$ Of 27 children, 14 (52\%) with vasodilatory septic shock had SMD, and none of the children in our study with VDEC shock had SMD. Serial monitoring for SMD could have probably shown a higher incidence. The EF on the echocardiography had a good correlation with the corresponding $\mathrm{Cl}$ obtained from electrocardiometry supporting the reliability of electrocardiometry.

This study adds to the recent literature that pediatric septic shock is predominantly vasodilatory shock; however, it may present as clinical cold shock due to relative hypovolemia and ventricular hypokinesia, which are frequent phenomena in severe sepsis. To diagnose the underlying hemodynamic state, facilitate targeted therapy, and optimize fluid resuscitation and vasoactive therapy, accurate and continuous monitoring of $\mathrm{CO}$ and systemic vascular resistance along with an assessment of fluid responsiveness is necessary. A noninvasive, continuous, and reliable monitoring device like electrocardiometry may be a promising adjunct to clinical examination and minimally invasive hemodynamic monitoring. It may promote a better understanding of the phenotypes of pediatric septic shock and their response to treatment, thus guiding the development of evidence-based management protocols.

Our study has some limitations. The small sample size may limit its generalizability. We did not analyze the data separately in children younger than 4 years due to the small sample size. Though electrocardiometry has already been validated in young children, ${ }^{17-23}$ it may be prudent to study these children separately as most of the other technologies including those based on the pulse contour analysis are less reliable in younger children. ${ }^{31}$ Also, electrocardiometry has not been validated against gold standard thermodilution techniques to assess $\mathrm{CO}$ in pediatric sepsis. Being a prospective observational study, we have not studied the implications of electrocardiometry monitoring on therapeutic decision-making. Whether noninvasive, continuous hemodynamic monitoring with electrocardiometry guides better management and improves patient-centered outcomes as compared to the current standard of care in pediatric septic shock management needs to be evaluated in future studies before being recommended for routine use. A cost-effective analysis may also be included in such a study. 
Electrocardiometry in Pediatric Septic Shock

Table 2: Comparison between fluid responders and nonresponders

\begin{tabular}{|c|c|c|c|c|}
\hline Parameter & Total $(n=30)$ & Responders $(n=16)$ & Nonresponders $(n=14)$ & $p$ value \\
\hline \multicolumn{5}{|l|}{ Severity illness scores } \\
\hline PRISM III score ${ }^{a}$ & $6.75(1.5,8.25)$ & $6(2,8)$ & $13.8(2.8,16.5)$ & 0.05 \\
\hline \multicolumn{5}{|l|}{ Clinical and biochemical parameters } \\
\hline Heart rate reduction postbolus $(/ \mathrm{min})^{\mathrm{b}}$ & $15.6 \pm 4.5$ & $18.4 \pm 4.5$ & $14.0 \pm 9.4$ & 0.24 \\
\hline MAP improvement postbolus $(\mathrm{mm} \mathrm{Hg})^{b}$ & $11.8 \pm 9$ & $13.5 \pm 8$ & $8.7 \pm 5.4$ & 0.23 \\
\hline Lactate prebolus $(\mathrm{mmol} / \mathrm{L})^{\mathrm{b}}$ & $4.2 \pm 3.3$ & $5.5 \pm 2.0$ & $4.6 \pm 3.5$ & 0.82 \\
\hline \multicolumn{5}{|l|}{ Electrocardiometry parameters } \\
\hline SVV before fluid bolus (\%) ${ }^{b}$ & $22.3 \pm 5.6$ & $24.1 \pm 5.2$ & $18.2 \pm 3.5$ & $<0.001$ \\
\hline Reduction in SVV after fluid bolus (\%) ${ }^{\mathrm{b}}$ & $8.1 \pm 5.1$ & $10.9 \pm 2.8$ & $6.0 \pm 4.5$ & 0.006 \\
\hline TFC before fluid bolus $(\mathrm{k} / \mathrm{ohm})^{\mathrm{b}}$ & $34.2 \pm 12.9$ & $34.2 \pm 8.2$ & $33.6 \pm 16.5$ & 0.54 \\
\hline Increase in TFC after fluid bolus (k/ohm) ${ }^{b}$ & $4.2 \pm 4.2$ & $2.3 \pm 1.8$ & $8.2 \pm 3.4$ & $<0.001$ \\
\hline \multicolumn{5}{|l|}{ Outcome parameters } \\
\hline Lactate clearance at $6 \mathrm{hrs}^{\mathrm{a}}(\%)$ & $33(27,60)$ & $55(28.6,58.6)$ & $25.4(6.5,35.8)$ & 0.03 \\
\hline VIS at 6 hrs $^{\mathrm{a}}$ & $30(20,120)$ & $30(25.5,50.5)$ & $82.5(20,120)$ & 0.043 \\
\hline Clinical resolution of shock at $6 \mathrm{hrs}^{\mathrm{c}}$ & $18(60)$ & $13(81)$ & $5(36)$ & 0.01 \\
\hline Clinical resolution of shock at $12 \mathrm{hrs}^{\mathrm{c}}$ & $21(70)$ & $15(93.7)$ & $6(42.8)$ & 0.01 \\
\hline Need for mechanical ventilation ${ }^{c}$ & $8(26.6)$ & $4(25)$ & $4(28.4)$ & 0.87 \\
\hline Duration of mechanical ventilation (days) ${ }^{a}$ & $8(2,10)$ & $3.5(1.3,3.8)$ & $5.5(1.5,7)$ & 0.34 \\
\hline Length of PICU stay in survivors (days) ${ }^{a}$ & $5(3,8)$ & $4(2,5)$ & $9.6(7.3,17)$ & 0.35 \\
\hline Mortality ${ }^{c}$ & $4(13.3)$ & $0(0)$ & $4(28.5)$ & 0.002 \\
\hline
\end{tabular}

${ }^{a}$ Median (interquartile range); ${ }^{b}$ Mean \pm standard deviation; ${ }^{c}$ Number (percentage); PRISM, pediatric risk of mortality; MAP, mean arterial pressure; SVV, stroke volume variation; TFC, thoracic fluid content; VIS, vasoactive-inotropic score; PICU, pediatric intensive care unit. The significant ' $p$ ' values are given in bold

\section{Conclusion and Clinical Significance}

In this pilot feasibility study, we could demonstrate that continuous, noninvasive hemodynamic monitoring using electrocardiometry permits comprehensive hemodynamic categorization and assessment of fluid responsiveness in pediatric septic shock. This may provide real-time guidance for optimal. Categorization of pediatric septic shock based on the $\mathrm{Cl}$ and SVRI into vasodilated or vasoconstrictive shock rather than clinical warm or cold shock may facilitate targeted resuscitation.

\section{Ethical Approval}

Approved by the institute ethics committee

\section{Device Manufacturer Name, Complete City and Country Name}

Osypka Medical GmbH, Berlin, Germany

\section{ORCID}

Swathi S Rao @ https://orcid.org/0000-0003-1127-9046 Lalitha AV (1) https://orcid.org/0000-0002-6168-1677 Mounika Reddy @ https://orcid.org/0000-0003-2270-022X Santu Ghosh 강 https://orcid.org/0000-0002-9373-9570

\section{References}

1. Aneja RK, Carcillo JA. Differences between adult and pediatric septic shock. Minerva Anestesiol 2011;77(10):986-992.

2. Weiss SL, Fitzgerald JC, Pappachan J, Wheeler D, JaramilloBustamante JC, Salloo A, et al. Global epidemiology of pediatric severe sepsis: the sepsis prevalence, outcomes, and therapies study. Am J Respir Crit Care Med 2015;191(10):1147-1157. DOI: 10.1164/ rccm.201412-23230C.

3. Davis AL, Carcillo JA, Aneja RK, Deymann AJ, Lin JC, Nguyen TC, et al. American college of critical care medicine clinical practice parameters for hemodynamic support of pediatric and neonatal septic shock. Crit Care Med 2017;45(6):1061-1093. DOI: 10.1097/ CCM.0000000000002425.

4. Brierley J, Peters MJ. Distinct hemodynamic patterns of septic shock at presentation to pediatric intensive care. Pediatrics 2008;122(4):752759. DOI: 10.1542/peds.2007-1979.

5. Ceneviva G, Paschall JA, Maffei F, Carcillo JA. Hemodynamic support in fluid-refractory pediatric septic shock. Pediatrics 1998;102(2):e19. DOI: 10.1542/peds.102.2.e19.

6. Ranjit S, Aram G, Kissoon N, Ali MK, Natraj R, Shresti S, et al. Multimodal monitoring for hemodynamic categorization and management of pediatric septic shock: a pilot observational study. Pediatr Crit Care Med 2014;15(1):e17-e26. DOI: 10.1097/PCC.0b013e3182a5589c.

7. Teboul JL, Saugel B, Cecconi M, De Backer D, Hofer CK, Monnet X, et al. Less invasive hemodynamic monitoring in critically ill patients. Intensive Care Med 2016;42(9):1350-1359. DOI: 10.1007/s00134-0164375-7.

8. Chaiyakulsil C, Chantra M, Katanyuwong P, Khositseth A, Anantasit $\mathrm{N}$. Comparison of three non-invasive hemodynamic monitoring methods in critically ill children. PLoS One 2018;13(6):e0199203. DOI: 10.1371/journal.pone.0199203.

9. Nguyen LS, Squara P. Non-invasive monitoring of cardiac output in critical care medicine. Front Med 2017;4:200. DOI: 10.3389/ fmed.2017.00200.

10. Klugman $D$, Berger JT. Echocardiography as a hemodynamic monitor in critically ill children. Pediatr Crit Care Med 2011;12:S50-S54. DOI: 10.1097/PCC.0b013e3182211c17.

11. Dellinger RP, Levy MM, Rhodes A, Annane D, Gerlach H, Opal SM, et al. Surviving sepsis campaign: international guidelines for 
management of severe sepsis and septic shock: 2012. Crit Care Med 2013;41(2):580-637. DOI: 10.1097/CCM.0b013e31827e83af.

12. Kelm DJ, Perrin JT, Cartin-Ceba R, Gajic O, Schenck L, Kennedy CC. Fluid overload in patients with severe sepsis and septic shock treated with early goal-directed therapy is associated with increased acute need for fluid-related medical interventions and hospital death. Shock 2015;43(1):68-73. DOI: 10.1097/SHK.0000000000000268.

13. Kattan E, Ospina-Tascón GA, Teboul JL, Castro R, Cecconi M, Ferri G. Systematic assessment of fluid responsiveness during early septic shock resuscitation: secondary analysis of the ANDROMEDA-SHOCK trial. Crit Care 2020;24(1):23. DOI: 10.1186/s13054-020-2732-y.

14. Monnet X, Marik PE, Teboul JL. Prediction of fluid responsiveness: an update. Ann Intensive Care 2016;6(1):111. DOI: 10.1186/s13613-0160216-7.

15. Desgranges FP, Desebbe O, Pereira de Souza Neto E, Raphael D, Chassard D. Respiratory variation in aortic blood flow peak velocity to predict fluid responsiveness in mechanically ventilated children: a systematic review and meta-analysis. Pediatr Anesth 2016;26(1):37-47. DOI: 10.1111/pan.12803.

16. Osypka MJ, Bernstein DP. Electrophysiologic principles and theory of stroke volume determination by thoracic electrical bioimpedance. AACN Clin Issues 1999;10(3):385-399. DOI: 10.1097/00044067199908000-00008.

17. Blohm ME, Obrecht D, Hartwic J, Mueller GC, Kersten JF, Weil J, et al. Impedance cardiography (electrical velocimetry) and transthoracic echocardiography for non-invasive cardiac output monitoring in pediatric intensive care patients: a prospective single-center observational study. Crit Care 2014;18(6):603. DOI: 10.1186/s13054014-0603-0.

18. Coté CJ, Sui J, Anderson TA, Bhattacharya ST, Shank ES, Tuason PM, et al. Continuous noninvasive cardiac output in children: is this the next generation of operating room monitors? Initial experience in 402 pediatric patients. Pediatr Anesth 2015;25(2):150-159. DOI: 10.1111/ pan.12441.

19. Malik V, Subramanian A, Chauhan S, Hote M. Correlation of electric cardiometry and continuous thermodilution cardiac output monitoring systems. World J Cardiovasc Surg 2014;04:101-108. DOI: $10.4236 /$ wjcs.2014.47016.

20. Rauch R, Welisch E, Lansdell N, Burrill E, Jones J, Robinson T, et al. Non-invasive measurement of cardiac output in obese children and adolescents: comparison of electrical cardiometry and transthoracic
Doppler echocardiography. J Clin Monit Comput 2012;27:187-193. DOI: 10.1007/s10877-012-9412-7.

21. Sanders M, Servaas S, Slagt C. Accuracy and precision of non-invasive cardiac output monitoring by electrical cardiometry: a systematic review and meta-analysis. J Clin Monit Comput 2019 (published online). DOI: 10.1007/s10877-019-00330-y.

22. Martin E, Anyikam A, Ballas J, Buono K, Mantell K, Huynh-Covey T, et al. A validation study of electrical cardiometry in pregnant patients using transthoracic echocardiography as the reference standard. J Clin Monit Comput 2016;30(5):679-686. DOI: 10.1007/s10877-015-9771-y.

23. Schmidt C, Theilmeier G, Aken H, Korsmeier P, Wirtz S, Berendes E, et al. Comparison of electrical velocimetry and transoesophageal doppler echocardiography for measuring stroke volume and cardiac output. Br J Anaesth 2005;95:603-610. DOI: 10.1093/bja/aei224.

24. Wong J, Agus MSD, Steil GM. Cardiac parameters in children recovered from acute illness as measured by electrical cardiometry and comparisons to the literature. J Clin Monit Comput 2013;27(1):81-91. DOI: 10.1007/s10877-012-9401-x.

25. Cattermole GN, Leung PYM, Ho GYL, Lau PWS, Chan CPY, Chan SSW, et al. The normal ranges of cardiovascular parameters measured using the ultrasonic cardiac output monitor. Physiol Rep 2017;5(6):e13195. DOI: $10.14814 /$ phy2.13195.

26. Marty P, Roquilly A, Vallée F, Luzi A, Ferré F, Fourcade $O$, et al. Lactate clearance for death prediction in severe sepsis or septic shock patients during the first 24 hours in intensive care unit: an observational study. Ann Intensive Care 2013;3(1):3. DOI: 10.1186/2110-5820-3-3.

27. McIntosh AM, Tong S, Deakyne SJ, Davidson JA, Scott HF. Validation of the vasoactive-inotropic score in pediatric sepsis. Pediatr Crit Care Med 2017;18(8):750-757. DOI: 10.1097/PCC.0000000000001191.

28. Hunter JD, Doddi M. Sepsis and the heart. Br J Anaesth 2010;104(1):311. DOI: 10.1093/bja/aep339.

29. Vieillard-Baron A. Assessment of right ventricular function. Curr Opin Crit Care 2009;15(3):254-260. DOI: 10.1097/MCC.0b013e32832b70c9.

30. Ranjit S, Natraj R, Kandath SK, Kissoon N, Ramakrishnan B, Marik PE. Early norepinephrine decreases fluid and ventilatory requirements in pediatric vasodilatory septic shock. Indian J Crit Care Med 2016;20(10):561-569. DOI: 10.4103/0972-5229.192036.

31. Suehiro K, Joosten A, Murphy LS, et al. Accuracy and precision of minimally-invasive cardiac output monitoring in children a systematic review and meta-analysis. J Clin Monit Comput 2016;30:603-620. DOI: 10.1007/s10877-015-9757-9. 